\title{
Household chemicals and pharmaceuticals - a lurking danger in home
}

\begin{abstract}
A commonly used household chemicals and pharmaceuticals agent who may range from pain killer remedies to anticonvulsant medications, hair-dye up to toilet cleaners - all agents poses a potentially fatal poisoning tendency. The most vulnerable groups in a household are children below 8 years of age to accidental poisoning and young adults to intentional self-harm; although, no age is barred from being poisoned by these agents. Children are most at risk for poison exposures from household products, as they do not have the ability to distinguish between safe and unsafe things that look very similar. This is an issue that can affect anyone where children are at most risk. This paper reviewed the present trend of household poisoning and observed that there is a striking increase in the number of household poisoning cases in the recent past. The primary aim of the present paper is to review the existing burden of 'household poisons' and to recommend appropriate preventive measures against such poisoning occurrences.
\end{abstract}

Keywords: household, chemical, pharmaceutical, cleaners, children, poison
Volume 5 Issue $3-2017$

\author{
Ambika Prasad Patra,' Kusa Kumar Shaha ${ }^{2}$ \\ 'AssistantProfessor,Departmentof Forensic Medicine \& \\ Toxicology, India \\ ${ }^{2}$ Additional Professor, Department of Forensic Medicine \& \\ Toxicology, India
}

\begin{abstract}
Correspondence: Ambika Prasad Patra, Assistant Professo Department of Forensic Medicine \& Toxicology, Jawaharlal Institute of Post-graduate Medical Education \& Research (JIPMER), Institute of National Importance under Ministry of Health \& FW, Government of India, JIPMER, Pondicherry, 605006, India, Tel 9092325535,

Email drambikajipmer@outlook.com
\end{abstract}

Received: July 13,2017 | Published: September II, 2017

\section{Background}

According to National Crime Records Bureau of India (NCRBI) report-2016, rat-killers and pesticides topped the list for 'household poisoning' so far last year, ousting mosquito coils and sprays and toilet cleaners in 2015 . The top five causing household poisoning this year also included toilet cleaner, thinner and lysol, glue and silica gel. ${ }^{1}$ In 2014 alone, the American Association of Poison Control Centers (AAPCC) reported that 2.2 million people came into contact with such substances, with calls made to a poison centre every 11 seconds. ${ }^{2}$ The Sunday Times learns (2015 study) with 281 females and 177 males making up patient numbers in 2015 . Of the 686 telephone enquiries made from the centre with regard to household poisoning, the majority (382) were for adults in the 20-60 year age-group, with children in the 3-14 year age-group (229) also being vulnerable. ${ }^{3-6} \mathrm{My}$ hospital is a national level hospital catering almost all of south India region, though cases are also being received from other corners of the country. In the year 2015, we had received a total of 420 number of household poisoning cases; while, this number had risen to 455 in 2016.

\section{Current scenario of household poisoning}

Accidental and unintentional poisonings occur in homes every day. Out of 455 cases we have received yet, 245 cases are suicide cases involving adults of age group 16 years to 58 years. The median is 22 years pointing towards higher numbers of young suicides. The rest 210 number of cases comprised of accidental poisoning cases. Surprisingly, the age group that fallen is between 2 years to 8 years, and the median age being 6 years. It is very serious concern that, the (poisoning) accidents in households are menacingly increasing among children, toddler age groups. Hence, to prevent such accidents, parents should be conscious that household poisoning could occur anywhere in home. The primary aim of the present paper is to review the existing burden of 'household poisons' and to recommend appropriate preventive measures for poisoning due to household agents. ${ }^{7-9}$

\section{Discussion}

The famous cliché 'the medicine cabinet, the lethal cabinet' should always be kept in mind, especially when the children are there in home. There are some typical social factors responsible for such drug over dosage seen in children caused by the 'medicine cabinet' in a household. Where there are grandchildren, likely that there could be grandparents in a household. Elderly members of house are more likely to are on some medications (that too scheduled drugs); and children are being exposed to such medicines. Children often find misplaced medication on nightstands, the floor or in purses, often in grandparents' or other relatives' homes. ${ }^{10}$ Medications, both prescription and over-the-counter drugs, are the cause of most poisonings. These include painkillers, sedatives, antidepressants, antihistamines, cardiovascular drugs, stimulants and vitamins/ supplements. ${ }^{11,12}$ If little bit carelessness is there among the parents. Therefore, children under age 6 are at the highest risk for poisoning - this age group accounted for 47 percent of exposures in my study.

Hence, If children are there in home, especially little ones under age 6, it's important to use the utmost care when storing and disposing of any poisonous products. Some household products, e.g. cleaning supplies, personal care products, prescription and over-the-counter medications, and the vast majority of products stored in garages, are so common, it's nearly impossible for most people to rid their home of poisonous substances, but there are ways to limit the risks. ${ }^{13,14}$ Cleaning substances are a known cause of dangerous poisonings. These include bleach, toilet and drain cleaner, polishes and waxes, allpurpose cleaners, dish soap and laundry detergent. Laundry detergent pods can be especially dangerous for children. Many are brightly coloured, small enough to be swallowed and contain a concentrated 
amount of product. If there is a toddler or a small child, whatever could cause poisoning should be kept out of reach and under lock and key of the parents. Nevertheless, the government and other stakeholders should take a concerted effort to prevent such poisoning and programs to make people aware of the dangers that may be lurking within their very homes. As its tools in spreading the message, the centre is using stakeholder meetings, seminars for the media, awareness campaigns through the distribution of CDs, posters and leaflets to peripheral health institutes frequented by men, women and children, lectures and educational exhibitions. ${ }^{15,16}$

\section{Thumbs rule to rule-out poisoning}

Sometimes, the poisoning in a household (especially among infants, toddlers) goes unwitnessed or unnoticed; parents come to know only when the child becomes symptomatic. In such circumstances the knowledge by the parents regarding some specific signs and symptoms or syndromes pertinent to specific poisoning will be helpful to the parents.

The following signs and symptoms in a child may be helpful to the parents, to rule out possibility of poisoning: ${ }^{17}$

1. Symptoms appearing within a short period after food or drink.

2. Symptomsappears suddenly in an otherwise healthy individual without any antecedent history.

3. In a family, if similar symptoms are seen in multiple family members.

4. Sudden onset of unexplained abdominal pain, nausea, vomiting, or diarrhea without any foreseeable reason.

5. Sudden, unexplained onset of drowsiness with or without fixed changes in pupil size (either dilated or pin-point, not reactive to light).

6. Unexplained, sudden onset of convulsions.

7. Sudden, unexplained onset of disorientation without fever or other foreseeable reasons.

8. Sudden, unexplained onset of paralysis in a young child.

\section{Recommendations} large ${ }^{18}$

The following tips may be helpful to prevent such incidences at

a. Be sure to properly store any medication, personal/cosmetic products and any other poisonous substance out of a child's reach and eyesight, and in sealed containers. Keep a close eye on children when in the homes of relatives and friends to avoid any swallowing hazards. Put all medication away and out of sight. This includes vitamins, supplements, eye drops and similar products that may not seem immediately dangerous. Also, take out the garbage immediately after throwing away anything that poses a poison hazard, such as cleaning wipes. Always follow product instructions and dispose of all medication and products properly, as outlined by the manufacturer.

b. Use any dosing devices that come with medication to avoid accidental overdoses, and never combine any medications without discussing it with your physician first. c. When using aerosols, always do so in spaces with lots of ventilation, and wear mouth/eye covers when appropriate.

d. Store cleaning products in their original containers and never combine them. Never mix cleaning products while using them. For instance, bleach- and ammonia-based products are both common, but when combined, they can create a toxic vapour.

e. Write clear instructions for caregivers about medication for children or aging adults living at home.

f. Be careful if you have a teen who is managing his or her own medicine. We have observed that teens self-administering overthe-counter medicine are a common reason for emergency room visits.

\section{Summary \& conclusion}

Any household, anywhere in the world is potential source of lethal poisons and toxins. The day-to-day usable articles ranging from medications up to the toilet cleaner are highly toxic substances; and amenable for poisoning. Both, intentional self-harm and accidents due to household agents are menacingly increasing. Children in six to eight year age group are more vulnerable for accidental exposure to household agents. Medications, cleaning agents and cosmetics are usual culprits for paediatric poisoning in a household. Young adults in 18-30 year age group showed high risk tendency of committing suicide using household agents, e.g. rodenticides, pesticides, hairdyes, etc. A multisectorial approach by the different stakeholders is required to educate parents and anti-suicidal counselling to the young adults, to prevent such incidences. Parents may seek help from the poison control centres (PCC) in case of emergency.

\section{Funding}

None.

\section{Acknowledgments}

None.

\section{Conflicts of interest}

The authors declare that there is no conflict of interest.

\section{References}

1. National Crime Records Bureau. Crime in India Statistics India. 2015

2. Watson WA, Litovitz TL, Reid N, et al. Annual Report of the American Association of Poison Control Centers Toxic Exposure Surveillance System. Am J Emerg Med. 2015;23:586-666.

3. Lawson GR, Craft AW, Jackson RH. Changing pattern of poisoning in children in newcastle. Br Med J (Clin Res Ed). 1983;287(6384):15-17.

4. Ahmed A, AlJamal AN. Poisoning emergency visits among children: a 3-year retrospective study in qatar. BMC Pediatr. 2015;15:104.

5. Andiran N, Sarikayalar F. Pattern of acute poisoning in childhood in ankara what has changed in twenty years. Turk J Pediatr. 2004;46(2):147-152.

6. Uziel Y, Adler A, Aharonowitz G, et al. Unintentional childhood poisoning in the sharon area in Israel: a prospective 5-year study. Pediatr Emerg Care. 2005;21(4):248-251.

7. Wilkerson R, Northington L, Fisher W. Ingestion of toxic substances by infants and children: what we don't know can hurt. Crit Care Nurse. $2005 ; 25(4): 35-44$ 
8. Mrvos R, Dean BS, Krenzelok EP. Illiteracy a contributing factor to poisoning. Vet Hum Toxicol. 1993;35(5):466-468.

9. Lam LT. Childhood and adolescence poisoning in NSW, Australia: an analysis of age, sex, geographic, and poison types. Inj Prev 2003;9(4):338342 .

10. Afshari R, Majdzadeh R, Balali-Mood M. Pattern of acute poisoning in Mashhad, Iran 1993-2000. J Toxicol Clin Toxicol. 2004;42(7):965-975.

11. Beirens TMJ, van Beeck EF. Unsafe storage of poisons in homes with toddlers. Accid Anal Prev. 2006;38(4):772-776.

12. Vassilev ZP, Marcus S, Jennis $\mathrm{T}$, et al. Rapid communication: sociodemographic differences between counties with high and low utilization of a regional poison control center. $J$ Toxicol Environ Health A. 2003;66(20):1905-1908.

13. Forrester MB. Association between sociodemographic factors and exposures and utilization of poison centers in Texas. 1998-2002. J Toxicol Environ Health. A 2005;68(10):755-761.
14. Mena C, Bettini M, Cerda P. Epidemiología de las intoxicaciones en Chile: una dé-cada de registros. Rev Méd Chile. 2004;132:493-499.

15. Repetto MR. Pediatric poisonings due to cleaning agents reported in to the toxicological information service of Seville. Spain Vet Hum Toxicol. 1994;38(6):435-437.

16. Runyan CW, Perkis D, Marshall SW, et al. Unintentional injuries in the home in the United States. Part II: morbidity. Am J Prev Med $2005 ; 28(1): 80-87$.

17. Pillay VV. Textbook of Forensic medicine \& toxicology. 18th ed. India: Paras publishers; 2017. p. 506-512.

18. World Health Organization. World report on child injury prevention. Switzerland: Department of Violence and Injury Prevention and Disability; 2015. p. 1-232. 